\title{
IMAGE ANALYSIS OF PEARLITE SPHEROIDIZATION BASED ON THE MORPHOLOGICAL CHARACTERIZATION OF CEMENTITE PARTICLES
}

\author{
Nicolas Nutal ${ }^{1}$, Cedric J Gommes ${ }^{2}$, Silvia Blacher ${ }^{2}$, Philippe Pouteau ${ }^{3}$, Jean-Paul \\ PIRARD $^{2}$, FRÉdÉRIC BOSCHINI ${ }^{1}$, KARL TRAINA ${ }^{1}$ AND Rudi ClOOTS ${ }^{1}$ \\ ${ }^{1}$ Laboratory of Structural Inorganic Chemistry, Chemistry Institute, University of Liège, Building B6a, B-4000 \\ Liege, Belgium; ${ }^{2}$ Department of Chemical Engineering, Chemistry Institute, University of Liège, Building B6a, \\ B-4000 Liege, Belgium; ${ }^{3}$ Center for Research in Metallurgy, Zwijnaarde, Technologiepark 903c, B- 9052 \\ Zwijnaarde, Belgium \\ e-mail: nutal@rdmetal.ulg.ac.be; cedric.gommes@ulg.ac.be; silvia.blacher@ulg.ac.be; pouteau@agt0.ugent.be; \\ jean-paul.pirard@ulg.ac.be; frederic.boschini@ulg.ac.be; karl.traina@ulg.ac.be; rcloots@ulg.ac.be \\ (Accepted May 10, 2010.)
}

\begin{abstract}
Pearlite spheroidization is a metallurgical process in steels by which cementite lamellae decompose into spheroids, a process accompanied by a decrease of the Vickers hardness of the samples. In this study, different methods are compared for measuring cementite particles length and width from scanning electron micrographs. Based on a test-image, a so-called ribbon-like method is proposed for measuring particles length and width, and for discriminating lamellae from spheroids. Differently heat-treated samples are prepared and characterized. The results of analysis are used to rationalize the evolution of the microstructure of the samples. Compared to the classical DeHoff shape factor, it is shown that new insight into the spheroidization process is gained by analyzing the lamellar length and width distributions.
\end{abstract}

Keywords: cementite spheroidization, lamellar structures, shape descriptors, Vickers hardness.

\section{INTRODUCTION}

Pearlitic steel consists of a soft ferrite matrix ( $\alpha$ $\mathrm{Fe})$ containing hard lamellar cementite $\left(\mathrm{Fe}_{3} \mathrm{C}\right)$. This material, which has interesting mechanical properties, finds many applications as railroad tracks, tyre cords, bridge cables, etc. These mechanical properties are related to interlamellar spacing (Gomes et al., 1997; Caballero et al., 2000; Elwazri et al., 2005), the pearlite colony size (Elwazri et al., 2006) as well as the prior austenite grain size (Elwazri et al., 2006).

Using a particular heat treatment, i.e., spheroidization annealing, lamellar cementite is transformed into spheroidized cementite (spheroidite). Thus, a distribution of cementite particles of different size is obtained. This transformation is accompanied by a modification of the mechanical properties. Indeed, as the lamellae break into smaller elements and spheroidize, the hardness drops (Krauss, 2005).

Traditionally, researchers followed this transformation by estimating the overall aspect ratio (Tian and
Kraft, 1987) of the cementite microstructure or by measuring the remaining fraction of lamellar cementite (O'Brien, 2000; O'Brien and Hosford, 2002). However, none of them attempts to describe the particular details of the microstructure, especially the lamellae length and width during the spheroidization.

In the present study, various methods were considered to measure the length and width of cementite particles. Based on a test-image containing typical cementite particles microstructures, a socalled ribbon-like method was selected. This method was used to analyze different heat-treated samples. Well known morphological parameter, i.e., DeHoff shape factor, was further calculated and compared with the samples characteristics obtained by the proposed method. These are mainly the lamellar ratio, representing the ratio between volume fraction of the lamellar particles and the total volume fraction of all cementite particles, and size distributions of lamellae and spheroids. The evolution of the microstructure during the spheroidization has been considered. Finally, lamellae size distributions were used to gain 
insight into the cementite lamellae spheroidization mechanism.

\section{MATERIALS AND METHODS}

Hypo-Eutectoid steel was investigated in this research. Its chemical composition was the following: C 0.7 wt.\%, Mn 1.5 wt.\%, Si 0.5 wt. $\%$, Mo $<0.1$ wt.\% and $\mathrm{Cr} 0.2$ wt.\%. The steel blocks were reheated at $1250{ }^{\circ} \mathrm{C}$ for $1 \mathrm{~h}$, then hot-rolled (30-20$12-7-3.8 \mathrm{~mm}$ ) and coiled at $680^{\circ} \mathrm{C}$. The steel was cold-rolled to a thickness of $1 \mathrm{~mm}$ and samples of $180 \times 20 \times 1 \mathrm{~mm}^{3}$ were cut. For spheroidizing annealing, the samples were annealed in nitrogen atmosphere at two different temperatures $\left(580^{\circ} \mathrm{C}\right.$ or $\left.650{ }^{\circ} \mathrm{C}\right)$ for different dwell times ( $2 \mathrm{~min}, 5 \mathrm{~min}, 11 \mathrm{~min}, 26 \mathrm{~min}$ and $60 \mathrm{~min}$ ) and water-quenched into water. The heating duration was 2 min and the accuracy of the heat controller was $\pm 4{ }^{\circ} \mathrm{C}$. Table 1 lists the sample identification and the corresponding heat treatment. The heat treatment parameters were chosen in order to produce microstructures ranging from predominantly lamellar to globular cementite.

Each sample was mounted in Polyfast type resin so that faces perpendicular to the rolling direction were analysed. The resins were abraded and polished down to a finishing grit of $0.25 \mu \mathrm{m}$. Vickers hardness indentations were performed using an Instron Wilson-Wolpert Tukon 2100B Hardness Tester, with a loading force of $0.5 \mathrm{kgF}(4.905 \mathrm{~N})$ and a dwell time of $10 \mathrm{~s}$. Twenty longitudinal hardness measurements were done on each sample. After the indentation measurements, the samples were etched with nital $\left(2 \% \mathrm{HNO}_{3}\right.$ in ethanol) for a few seconds in order to reveal the microstructure. For each sample, seven high resolution secondary electron micrographs (8192×6400 pixels grid) were recorded on a Philips FEG-ESEM XL30 at a $1500 \times$ magnification. The observed surface was located outside of the regions deformed by hardness measurement. Fig. 1a shows the initial lamellar microstructure (sample IS), Fig. 1b shows intermediary structure consisting of short lamellae and spheroids (sample I5) and Fig. 1c shows mainly globular microstructure (sample I10).

The image analysis used in the present work is based on classical tools of mathematical morphology (Soille, 1999). It was implemented with Matlab 7.1, together with its image processing toolbox.

\section{IMAGE ANALYSIS}

The first step of the analysis was the image segmentation, which aimed at discriminating pixels from the cementite and the ferrite phases. The result of image segmentation is shown in Fig. 2a for the sample IS. It was obtained as follows. First, a median filter with a square kernel of size 3 was applied to reduce the salt-and-pepper noise. Top-hat filtering with a square structuring element of size 20 , followed by a bottom-hat filtering with a structuring element of size 30 , were used to further enhance the image contrast. The obtained image was then segmented with a threshold computed with Otsu's method (Otsu, 1979). It may happen, especially at an early stage of spheroidization, that two distinct lamellae touch each other by just a few pixels. In order to remove these touching pixels and to separate lamellae, an opening filter with a square structuring element of size 3 was applied. The smallest objects having a surface less than 30 pixels were then removed by an area opening filter. Finally, the holes in the remaining white objects were filled.
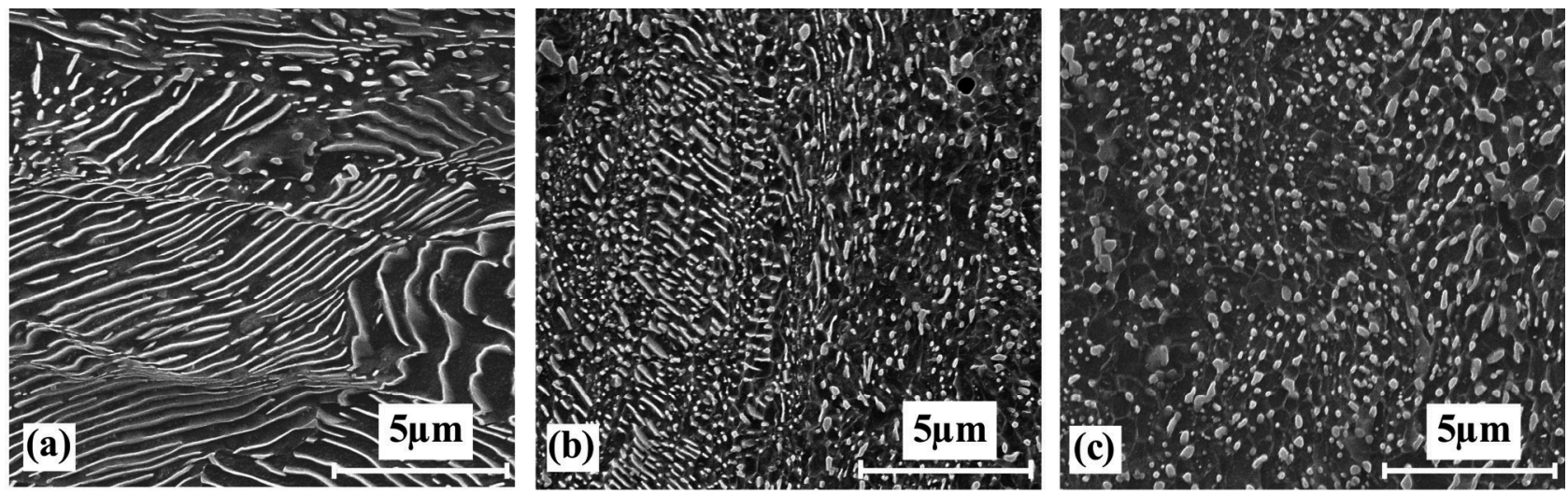

Fig. 1. Electron micrographs of the samples IS (a), I5 (b) and IIO (c) showing typical microstructure observed during spheroidization step. Secondary electron mode pictures, magnification: $1500 \times$. These pictures represent around $4 \%$ of the area of the original images. 

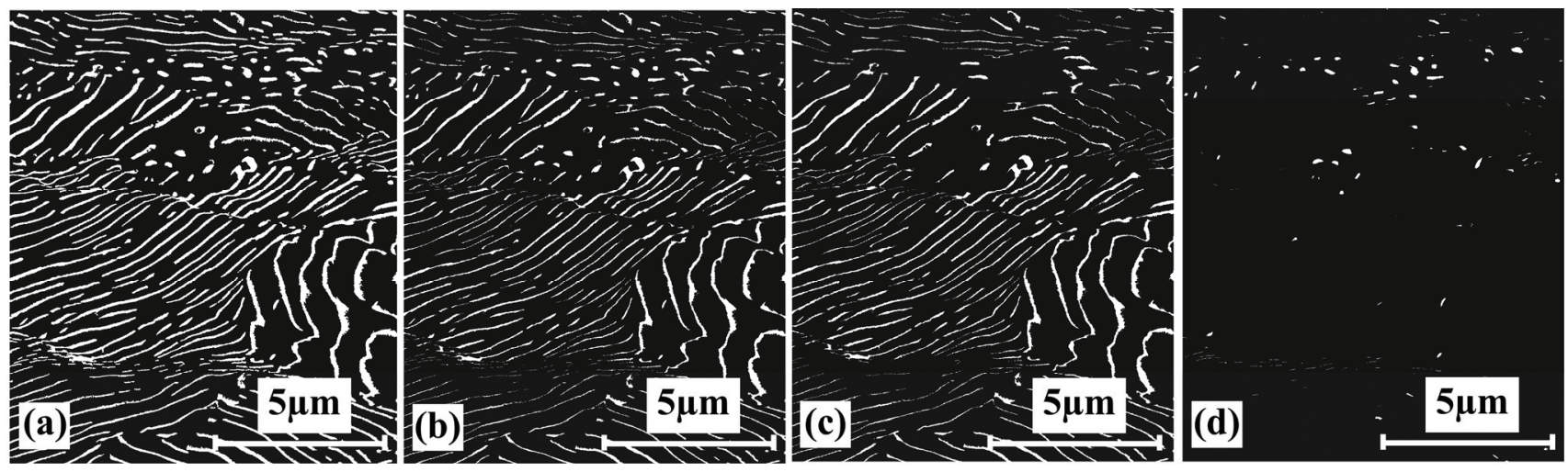

Fig. 2. Processed image and particles selection (sample IS, magnification 1500×): (a) Segmented image obtained as described in text; (b) Segmented after thinning towards total cementite fraction of 0.102; (c) lamellar element picture $\left(L_{r} / W_{r}>8\right)$ and (d) spheroidized elements picture $\left(L_{r} / W_{r}<8\right)$. These pictures represent around $4 \%$ of the area of the original images.

In order to compare the fraction of cementite in the segmented images, $V_{V}$, with the actual fraction of cementite in the steel, $V_{V}^{C}$, the latter was estimated by the lever rule (Krauss, 2005) as

$$
V_{V}^{C}=\frac{C_{0}-C_{\alpha}}{C_{\mathrm{Fe}_{3} \mathrm{C}}-C_{\alpha}},
$$

where $C_{\mathrm{Fe}_{3} \mathrm{C}}$ is the content of carbon of the cementite $(6.67 \mathrm{wt} . \% \mathrm{C}) ; \mathrm{C}_{\alpha}$ is the carbon content of ferrite $(0.02$ wt. $\% \mathrm{C}$ ) and $\mathrm{C}_{0}$ is the carbon content of hypoeutectoid steel. The carbon content of the initial steel is 0.7 wt.\%C. Consequently, the volume fraction of cementite in the samples is around $10.2 \%$. At this step of the image processing, the overall fraction of cementite in the segmented images $V_{V}$ is larger than that value. This overestimation was expected, as notably discussed by Chattopadhyay and Sellars (1977): as the lamellae are not perpendicular to the surface, they are generally imaged under a finite angle, which, because of etching depth effect, leads to an overestimation of their thickness. A similar reasoning applies to spheroidal particles, the radius of which is overestimated. In order to correct these effects, a morphological thinning has been used to decrease the total area of cementite particles and make it as close as possible to the theoretical value $(10.2 \%)$. The result of the thinning is illustrated in the Fig. 2b.

Once the segmented image has been obtained, the stereological factor $F$ proposed by DeHoff (1964) and generalized by Fischmeister (1974) was measured. It was estimated as

$$
F=\frac{2 N_{L}^{2}}{3 \pi V_{V} N_{\mathrm{A}}}
$$

where $N_{\mathrm{L}}$ is the number of cementite surfaces intersected per unit test line, $N_{\mathrm{A}}$ is the number of cementite particles intersected per unit test area and $V_{V}$ is the volume fraction of cementite particles. DeHoff shape factor $F$ is a global image characteristic, which takes high values for elongated structures and converges to one in the case of a perfectly isotropic structure.

In addition to this global stereological procedure, another option for quantifying the structures in the segmented images consists in discriminating lamellar from globular objects, and in characterising them individually. Chattopadhyay and Sellars (1977) proposed to discriminate the lamellae from the spheroids based on the length over width ratio: objects are considered to be spheroids if their length to width ratio is lower than 8 . In order to separate lamellae and spheroids based on this criterion, the length and width of each individual cementite particle must be measured. Three alternative methods were explored. The first method consists of calculating the skeleton of the particles, and of measuring the length of the particle's pruned skeleton (Russ, 2006). The second method consists of measuring the major axis length of the ellipsoid of inertia of each particle (Russ, 2006). The third and final method is based on the assumption that the particles are ribbon-like, which enables one to estimate the length $\left(L_{\mathrm{r}}\right)$ or width $\left(W_{\mathrm{r}}\right)$ using:

$$
L_{\mathrm{r}}=\frac{1}{2}\left(\frac{P}{2}+\sqrt{\left(\frac{P}{2}\right)^{2}-4 A}\right)
$$


and

$$
W_{\mathrm{r}}=\frac{1}{2}\left(\frac{P}{2}-\sqrt{\left(\frac{P}{2}\right)^{2}-4 A}\right),
$$

where $A$ and $P$ are respectively the area and perimeter of the particle.

Taking into account the various shapes of the cementite particles, a test image (Fig. 3) has been created containing the different types of regions that can be met in the images: straight (Fig. 3a), curved (Fig. 3b) and cranked (Fig. 3c). The different methods proposed above were tested on each object and the respective results are drawn in the Fig. 3: the red line inside the original shapes corresponds to the skeleton method, the oval blue shapes are the equivalent ellipsoids of inertia and the yellow rectangles are the equivalent ribbons.

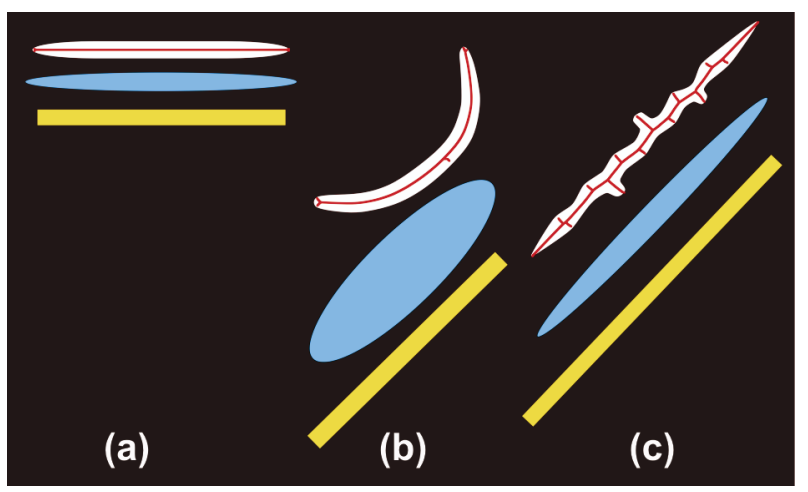

Fig. 3. Test image containing possible morphologies of cementite particle (in white): straight (a), curved (b) and cranked (c). The different methods proposed to estimate particle length are the skeleton (red line inside the original shapes), the equivalent ellipsoid of inertia (blue shape) and the equivalent ribbon (yellow shape).

Each of the length measuring methods is based on specific geometrical assumptions, and works differently on the different types of objects shown in Fig. 3. The method based on skeletonization is very sensitive to the roughness of the lamellar elements (Fig. 3c) and the pruning required to remove the spurs may lead to an underestimation of the length. Moreover no information on particle width is obtained. Therefore, this method should be rejected. For curved elements (Fig. 3b), the method referring to the ellipsoid of inertia underestimates the length and overestimates the width. Given the microstructure of cementite, see Fig. 1a, this method should also be rejected. The ribbon-like method overestimates the length of cranked particle, but only by a small amount. For the curved and straight elements, the response is more accurate than with the other two methods. Taking into account the various advantages and drawbacks cited above, the ribbon-like method has been chosen for particle length and width measurements.

For every cementite particle, the length and width were then measured according to Eq. 3 and Eq. 4, respectively. Following Chattopadhyay and Sellars (1977), the cementite particles were then classified as lamellar if their length to width aspect ratio was larger than 8 and as globular otherwise. An example of discrimination between lamellae and spheroids is shown in Fig. 2c and 2d.

Different morphological parameters were estimated to characterize the microstructure of the cementite phase during the cementite spheroidization. The area, length and width of lamellar particles were measured. The area and the equivalent diameter of spheroidal particles were determined. To characterize the progress of the transformation, the lamellar ratio of lamellar particles, $\mathrm{L}_{\text {ratio, }}$ was calculated according to Eq. (5).

$$
L_{\text {ratio }}=\frac{V_{V}^{L}}{V_{V}} .
$$

$\mathrm{L}_{\text {ratio }}$ is the parameter representing the volume fraction of lamellar cementite particles $V_{V}^{L}$ (Fig. 2c) standardised against the total volume fraction of cementite particles $V_{V}$ (Fig. 2b). This standardisation is applied in order to take account of the small discrepancies in the total volume fraction of cementite particles measured in the samples.

\section{RESULTS}

The stereological parameters $\left(V_{V}, N_{\mathrm{A}}\right.$ and $\left.N_{\mathrm{L}}\right)$ used to estimate DeHoff shape factor $(F)$ are shown in Table 1 together with the lamellar ratio $\mathrm{L}_{\text {ratio }}$ and Vickers hardness of each sample. The slight deviations of $V_{V}$ from the actual value $10.2 \%$ are not statistically significant, as testified by the estimation error on that parameter. 
Table1. Sample identification, spheroidizing parameters, image analysis results and Vickers hardness.

\begin{tabular}{|c|c|c|c|c|c|c|c|c|}
\hline \multirow[t]{2}{*}{ Sample } & \multirow{2}{*}{$\begin{array}{c}\text { Dwell } \\
\text { temperature } \\
\left({ }^{\circ} \mathrm{C}\right)\end{array}$} & \multirow{2}{*}{$\begin{array}{c}\text { Dwell } \\
\text { time } \\
\text { (min) }\end{array}$} & \multicolumn{4}{|c|}{ DeHoff shape factor } & \multirow[t]{2}{*}{$\mathrm{L}_{\text {ratio }}$} & \multirow{2}{*}{$\begin{array}{c}\text { Vickers } \\
\text { Hardness } \\
(\mathrm{HV})\end{array}$} \\
\hline & & & $V_{V}$ & $\begin{array}{c}N_{\mathrm{A}} \\
\left(\mu \mathrm{m}^{-2}\right)\end{array}$ & $\begin{array}{c}N_{\mathrm{L}} \\
\left(\mu \mathrm{m}^{-1)}\right)\end{array}$ & $F$ & & \\
\hline IS & / & / & $0.107 \pm 0.011$ & $5.0 \pm 0.3$ & $4.7 \pm 0.3$ & $8.8 \pm 0.4$ & $0.86 \pm 0.01$ & $378 \pm 5$ \\
\hline I1 & 580 & 2 & $0.099 \pm 0.008$ & $5.5 \pm 0.5$ & $3.4 \pm 0.1$ & $4.5 \pm 0.3$ & $0.77 \pm 0.02$ & $360 \pm 3$ \\
\hline $\mathrm{I} 2$ & 580 & 5 & $0.108 \pm 0.008$ & $4.9 \pm 0.3$ & $2.9 \pm 0.1$ & $3.4 \pm 0.1$ & $0.71 \pm 0.02$ & $345 \pm 4$ \\
\hline I3 & 580 & 11 & $0.103 \pm 0.009$ & $5.9 \pm 0.4$ & $3.0 \pm 0.1$ & $3.1 \pm 0.1$ & $0.67 \pm 0.02$ & $342 \pm 2$ \\
\hline I4 & 580 & 26 & $0.096 \pm 0.004$ & $5.4 \pm 0.3$ & $2.7 \pm 0.1$ & $3.0 \pm 0.1$ & $0.65 \pm 0.03$ & $333 \pm 7$ \\
\hline I5 & 580 & 60 & $0.109 \pm 0.005$ & $5.1 \pm 0.2$ & $2.6 \pm 0.2$ & $2.5 \pm 0.2$ & $0.56 \pm 0.06$ & $318 \pm 2$ \\
\hline I6 & 650 & 2 & $0.109 \pm 0.005$ & $5.8 \pm 0.2$ & $2.9 \pm 0.1$ & $2.9 \pm 0.2$ & $0.60 \pm 0.03$ & $326 \pm 3$ \\
\hline I7 & 650 & 5 & $0.094 \pm 0.002$ & $6.1 \pm 0.2$ & $2.7 \pm 0.1$ & $2.8 \pm 0.1$ & $0.53 \pm 0.02$ & $313 \pm 5$ \\
\hline I8 & 650 & 11 & $0.104 \pm 0.006$ & $5.1 \pm 0.2$ & $2.4 \pm 0.1$ & $2.5 \pm 0.2$ & $0.49 \pm 0.04$ & $297 \pm 5$ \\
\hline I9 & 650 & 26 & $0.101 \pm 0.005$ & $4.7 \pm 0.3$ & $2.3 \pm 0.1$ & $2.4 \pm 0.2$ & $0.45 \pm 0.05$ & $285 \pm 3$ \\
\hline $\mathrm{I} 10$ & 650 & 60 & $0.099 \pm 0.005$ & $3.8 \pm 0.2$ & $1.9 \pm 0.1$ & $2.3 \pm 0.1$ & $0.39 \pm 0.02$ & $277 \pm 2$ \\
\hline
\end{tabular}
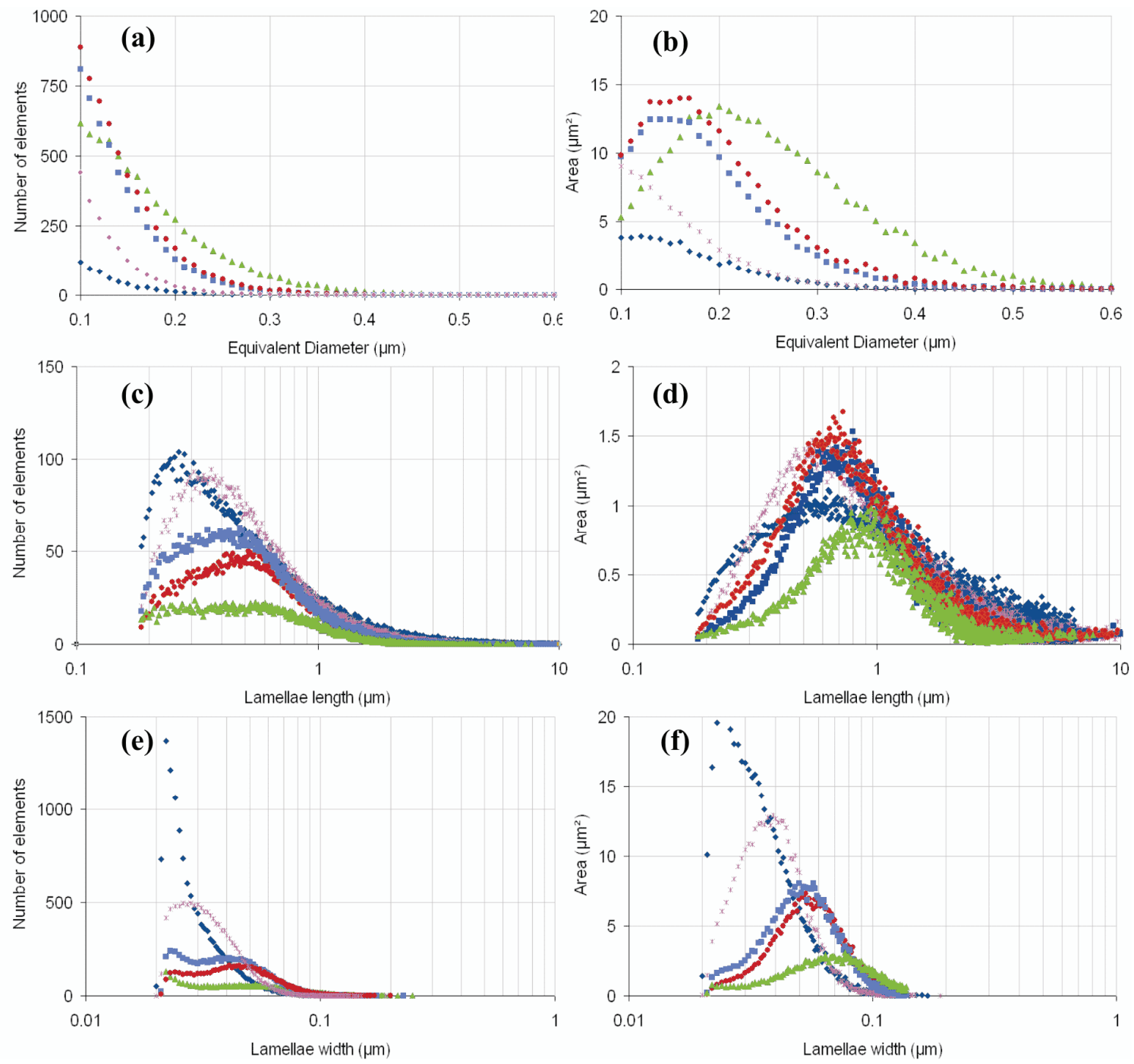

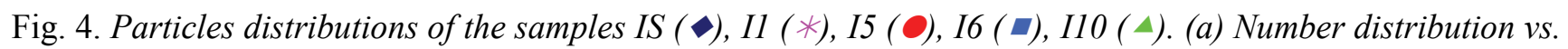
Equivalent diameter for globular elements; (b) Area distribution vs. Equivalent diameter for globular elements; (c) Number distribution vs. Length for lamellar particles; (d) Area distribution vs. length for lamellar particles. (e) Number of lamellae vs. Lamellae width; (f) Area of lamellae vs. Lamellae width. An area of $0.0367 \mathrm{~mm}^{2}$ has been investigated on every sample section. 
In order to identify the distinctive characteristics of samples, the equivalent diameters of the spheroids, as well as the length and width of the lamellae, were measured. Samples IS, I1, I5, I6 and I10 are shown in Fig. 4, because their evolution is representative of the entire process. Figs. $4 \mathrm{a}, 4 \mathrm{c}$ and $4 \mathrm{e}$ show the numberweighted distributions, whereas Figs. $4 \mathrm{~b}, 4 \mathrm{~d}$ and $4 \mathrm{f}$ show the area-weighted distributions. As discussed further below, the former distributions give some insight into the morphological changes induced by the spheroidization, while the latter enable to quantify the global extent of spheroidization.

\section{DISCUSSION}

For low spheroidizing temperature $\left(580^{\circ} \mathrm{C}\right)$, the number of particles per unit test area $\left(N_{\mathrm{A}}\right)$ remains nearly constant indicating slow transformation kinetics (see $N_{\mathrm{A}}$ in the Table 1, samples I1 to I5). For the samples spheroidized at $650{ }^{\circ} \mathrm{C}$, the number of particles per area $N_{\mathrm{A}}$ first increases slightly (see Table 1, samples I6 and I7), and then decreases over longer spheroidization times (samples I8 to I10). This can be probably explained by the coarsening process which takes place. It can be also seen that the number of cementite surfaces intersected per unit test line (see $\left.N_{\mathrm{L}}\right)$ decreases with time for both temperatures $\left(\right.$ see $N_{\mathrm{A}}$ on the Table 1, samples I1 to I5 and samples I6 to I10).

DeHoff shape factor $F$ and the lamellar ratio $\mathrm{L}_{\text {ratio }}$ undergo the same qualitative changes during the heat treatment, i.e., for equal dwell temperatures, both values decrease as the spheroidization time increases and for identical dwell times, they both decrease when the transformation temperature is increased. Both morphological parameters are related to the change of microstructure: the lamellae break up into smaller elements and then spheroidize.

Figs. $5 \mathrm{a}$ and $5 \mathrm{~b}$ compare the dependence of DeHoff shape factor $F$ and the lamellar ratio $\mathrm{L}_{\text {ratio }}$ on the measured Vickers hardness of the samples. A priori, a correlation was not clearly expected between the hardness of the steel and the morphology of the cementite phase because the initial samples had been cold-rolled, which increased the hardness of the ferrite phase in an unpredictable way. Therefore two processes are actually at play during the heat treatment, namely the spheroidization of the cementite phase and the recrystallization of the ferrite, both of which should decrease the hardness. Surprisingly, however, it can be seen from Fig. 5 that the observed changes in hardness can be to a large extent explained by the morphological changes of the cementite phase. Moreover, DeHoff shape factor $F$ is found to be very sensitive to the microstructural changes at the beginning of cementite spheroidization (Fig. 5a and samples ISI1 in Table 1), while $\mathrm{L}_{\text {ratio }}$ is proportional to the hardness of the samples throughout the entire spheroidization process (Fig 5b).
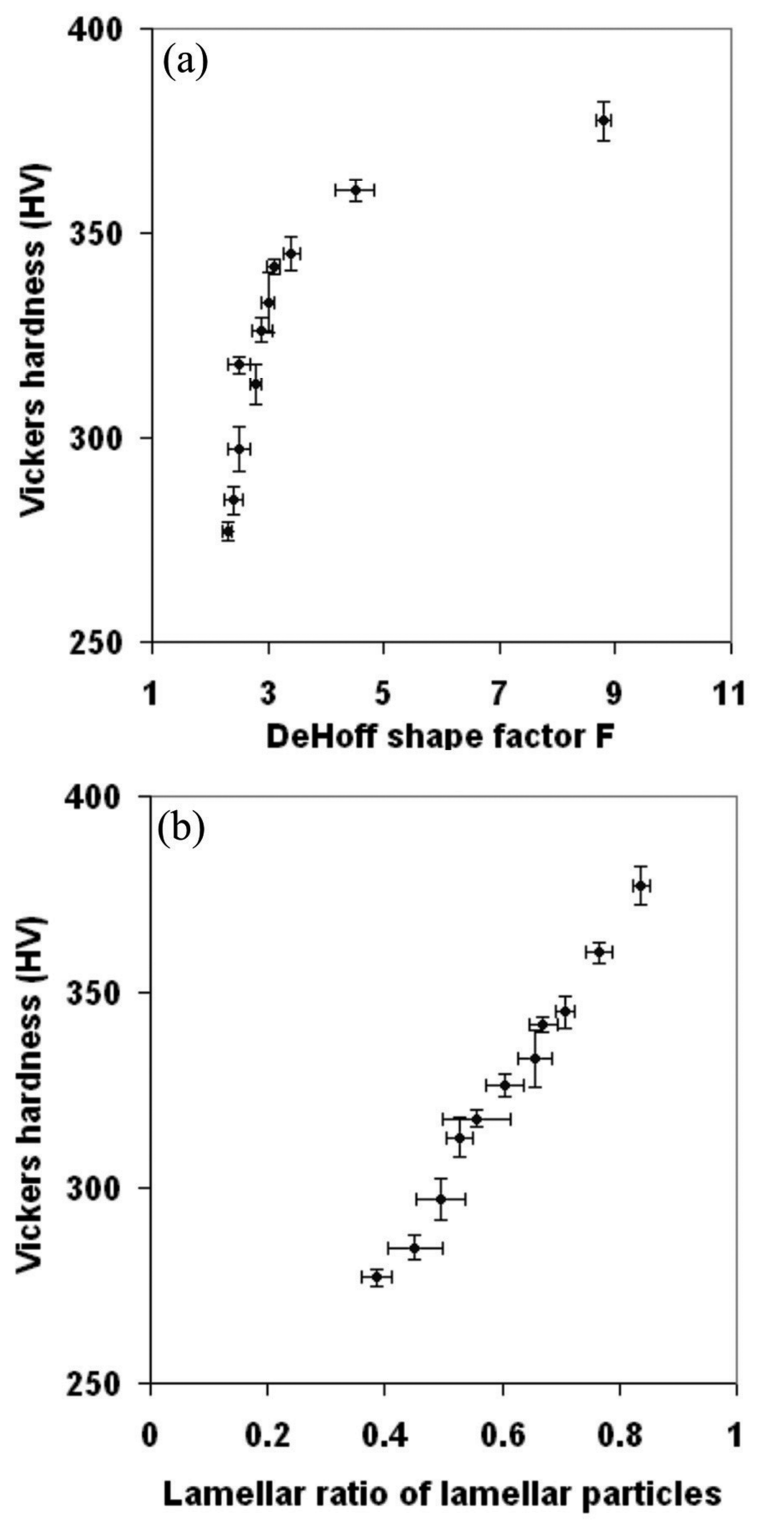

Fig. 5. (a) Vickers hardness vs. DeHoff shape factor value and (b) Vickers hardness vs. Lamellar ratio of lamellar particles.

More insight into the details of the spheroidization process can be obtained by analyzing the size distributions of lamellae and spheroids (Fig. 4). As the spheroidization begins, the number of small globular particles with diameter between 0.1 and 0.2 $\mu \mathrm{m}$ increases rapidly (Fig. 4a: curves I1 and I6 in comparison with IS). As expected, this increase is faster for the sample I6 because the lamellae spheroidization kinetic is temperature dependent. After this 
sharp increase, the production of globular particles slows down and the coarsening of the globular particles, which is temperature dependent (Sakuma et al., 1980; Lindsley and Marder, 1997), occurs (Fig. 4a: curves I1 and I5 and curves I6 and I10). Therefore, the most probable diameter of the cementite spheroids for the samples heat-treated for $60 \mathrm{~min}$ is shifted to larger values (Fig. 4b: curves I5 and I10).

These evolutions of spheroidized particles expressed in number or in area are directly related to the lamellar cementite microstructural changes. It can be seen that the number of short lamellae, with a size around 0.4 to $0.7 \mu \mathrm{m}$, remains nearly constant at the beginning of the spheroidization transformation (Fig. $4 \mathrm{c}$, curve I1); at the same time, the number of very long lamellae decreases (Fig. 4d, curve I1). The number of short lamellae starts decreasing soon afterwards, as their spheroidization occurs (Fig. 4c, curve I1 and I5).

For the samples heat treated at $650{ }^{\circ} \mathrm{C}$, it can be observed that the number of long lamellae decreases rapidly (Fig. 4c, curves IS to I6). Then, the lamellae length distribution flattens as the lamellae breaks into smaller elements and spheroidize (Fig. 4d, curve I10). It is interesting to note that even if the spheroidization of lamellae occurs, the most frequent lamellae length, around $0.8-0.9 \mu \mathrm{m}$, remains almost unchanged. The spheroidization is a process that involves mostly exceptionally long lamellae, which are apparently the least stable.

Lamellae width distributions give interesting information on lamellae spheroidization mechanism. The Fig. 4e shows that thin lamellae disappears preferentially as the dwell duration increases (curves I1 to I5 and I6 to I10). Indeed, thin lamellae have the largest surface over volume ratio and they are therefore expected to be the least stable due to their higher interfacial energy. In order to reduce their interfacial energy, the remaining lamellae thicken and the most probable width of the lamellae shifts to larger values (Figs. $4 \mathrm{e}$ and $4 \mathrm{f}$ ).

It is also interesting to note that the lamellae length distribution for the sample I10 is bimodal (see on Figs. $4 \mathrm{c}$ and $4 \mathrm{~d}$ ), with a light mix-up at about 0.3 $\mu \mathrm{m}$. A shoulder located at the same length is visible also in the distributions of samples I5 and I6 (Fig. $4 \mathrm{c})$. The same observations may be done for lamellae width distributions (see curves I10 in Figs. 4e and 4f), in which the transition is located at $0.02 \mu \mathrm{m}$. A shoulder is clearly visible too for the curves I5 and I6. Therefore, it seems that the lamellae go through a transition state (with length about $0.3 \mu \mathrm{m}$ and width $0.02 \mu \mathrm{m}$ ) before being transformed into spheroids.

\section{CONCLUSIONS}

In the present study, the cementite particles morphology of pearlitic steel samples was investigated at various stages of the spheroidization process. Representative images of the samples obtained from scanning electron micrographs were analyzed with image analysis.

Different methods for measuring particles length and width, especially lamellae, were compared and the ribbon-like method was found the most suitable. It was shown that the lamellar length distributions give physical insight into the spheroidization process. In particular, the spheroidization starts with the breaking of exceptionally long lamellae, while the most frequent lamellae length remains mostly unchanged during the process. Lamellae width distributions confirm that thin lamellae disappear first. Then the remaining lamellae thicken in order to decrease their interfacial energy.

Moreover, using the aspect ratio proposed by Chattopadhyay and Sellars (1977) to discriminate lamellae from spheroids, it seems that the cementite spheroidization goes through a transitive state, corresponding to lamellae with a length about $0.3 \mu \mathrm{m}$ and width about $0.02 \mu \mathrm{m}$. Further investigation is needed to confirm this last result, in particular to check its robustness to the criterion applied for discriminating lamellae from spheroids.

Concerning the practically important issue of the relation between the spheroidization and the hardness of the steel, our results globally confirm the relevance of morphological parameters such as the DeHoff shape factor $F$ or the lamellar ratio $\mathrm{L}_{\text {ratio. }}$. Surprisingly, the relevance of these parameters holds also for coldrolled steels, which are subject to ferrite recrystallization. At the beginning of the transformation, the DeHoff shape factor $F$ seems to be more sensitive to the cementite spheroidization than the lamellar ratio $\mathrm{L}_{\text {ratio. }}$ Lamellar ratio is found to be proportional to the hardness of the samples throughout the entire spheroidization process.

\section{ACKNOWLEDGEMENT}

N.N. is grateful to the Centre de Recherches Métallurgiques (Liège, Belgium) for a research grant; CJG is a postdoctoral researcher of the Fonds National de la Recherche Scientifique (F.R.S.-FNRS, Belgium). 
The authors are also obliged to Dr. Catherine Henrist for her help when using the electron microscope facilities (Cellule d'Appui Technologique en Microscopie, University of Liège, Belgium). Support from the Belgian research program "Poles d'Attraction Inter-Universitaires" PAI 6/17 is also acknowledged.

\section{REFERENCES}

Caballero FG, de Andres CG, Capdevila C (2000). Characterization and morphological analysis of pearlite in a eutectoid steel. Mater Charact 45:2:111-6.

Chattopadhyay S, Sellars CM (1977). Quantitative measurements of pearlite spheroidization. Metallography 10: 89-105.

DeHoff RT (1964). The determination of the geometric properties of aggregates of constant-size particles from counting measurements made on random plane section. Trans AIME 230:764-9.

Elwazri AM, Wanjara P, Yue S (2005). The effect of microstructural characteristics of pearlite on the mechanical properties of hypereutectoid steel. Mater Sci Eng A 404:91-8.

Elwazri AM, Wanjara P, Yue S (2006). Empirical modelling of the isothermal transformation of pearlite in hypereutectoid steel. Mater Sci Technol 22:542-6.
Fischmeister HF (1974). Shape factors in quantitative microscopy. Z Metallkd 65:558-62.

Gomes MDMD, de Almeida LA, Gomes LCFC, Le May I (1997). Effects of microstructural parameters on the mechanical properties of eutectoid rail steels. Mater Charact 39:1-14.

Krauss G (2005). Steels: Processing, Structure, and Performance. Ohio: ASM International.

Lindsley A, Marder AR (1997). The morphology and coarsening kinetics of spheroidized Fe-C binary alloys. Acta Mater 46:341-51.

O'Brien JM (2000). PhD Thesis: Spheroidizing of medium carbon steels. University of Michigan.

O'Brien JM, Hosford WF (2002). Spheroidization cycles for medium carbon steels. Metall Mater Trans A 33:1255-61.

Otsu N (1979). A threshold selection method from graylevel histograms. IEEE Trans Syst Man Cyber 9:62-6.

Russ JC (2006). The image processing handbook. Boca Raton: CRC Press.

Sakuma T, Watanabe N, Nishizawa T (1980). The effect of alloying element on the coarsening behaviour of cementite particles in ferrite. Trans Jim 21:159-68.

Soille P (1999). Morphological image analysis. Berlin, Heidelberg, New-York: Springer-Verlag.

Tian YL, Kraft RW (1987). Kinetics of pearlite spheroidization. Metall Mater Trans A 18A:1359-69. 